\title{
Evaluación de la expresión de ARNm de genes virales E2, E6 y E7 como marcadores predictivos de progresión en lesiones producidas por VPH 16.
}

\author{
Angel Mauricio Vitriago-Rendón ${ }^{1}$, Marwan Said Aguilar-Mejía ${ }^{2}$, Pedro José Michelli-Gagó2, \\ Joseba Celaya Linaza $a^{2}$ y Cristina Gutiérre: ${ }^{3}$ \\ ${ }^{1}$ Banco Municipal de Sangre del Distrito Capital. Caracas, Venezuela. \\ ${ }^{2}$ Laboratorio de Patología Molecular, Cátedra de Anatomía Patológica, Escuela Luis \\ Razzetti, Facultad de Medicina, UCV. Caracas, Venezuela. \\ ${ }^{3}$ Cátedra de Virología, Departamento de Microbiología, Facultad de Medicina, UCV. \\ Caracas. Venezuela.
}

Palabras clave: VPH; RT-qPCR; oncogenes; ARNm; E2; E6; E7.

Resumen. El Virus del Papiloma Humano (VPH) pertenece a un grupo de virus con $\mathrm{ADN}$ de doble cadena, con 35 genotipos capaces de infectar el epitelio de superficies cutáneas en todo el cuerpo y mucosas del área ano-genital. El genotipo 16 es clasificado como un VPH de alto riesgo oncogénico y ha sido identificado con más frecuencia en infecciones y carcinomas cérvico-uterinos. El objetivo planteado en este trabajo fue evaluar la expresión de los ARNm virales como indicadores de progresión de las lesiones intraepiteliales (LIE), causadas por VPH 16. Se procedió a la determinación y cuantificación de los ARNm de los genes virales E2, E6 y E7 mediante el uso de una prueba de reacción en cadena polimerasa con transcriptasa inversa cuantitativa en tiempo real (RT-qPCR). El VPH 16 se detectó en un 31,58\% (12/38) del total de pacientes; en las lesiones de bajo grado se observó en un 29,63\% y en las de alto grado, en un 36,36\% de los casos. El total de ARNm viral cuantificado aumentó al incrementarse la cantidad de VPH oncogénicos presentes en la muestra $\left(\mathrm{R}^{2}=0,51\right)$. Se encontró una correlación $\left(\mathrm{R}^{2}=0,36\right)$, entre la expresión del ARNm del Gen E7 y la progresión del grado de la lesión. Se llegó a la conclusión que, la expresión de ARNm de los genes virales E6 y E7 pudieran ser utilizados en el futuro para la evaluación efectiva de la progresión en las lesiones de pacientes infectados por VPH 16 para así lograr la diferenciación de las lesiones pre-cancerosas.

Autor de correspondencia: Angel Vitriago. Banco Municipal de Sangre del Distrito Capital, Esquina de Pirineos. San José, detrás del Hospital José María Vargaas. Caracas, Venezuela. Teléfono: 0212-861.31.79 / 0424-258.56.90. E-mail: ang.mau.vit.ren@gmail.com 


\title{
Evaluation of viral genes E2, E6 and E7 mRNA expression as predictive markers of progression of lesions caused by HPV 16.
}

\author{
Invest Clin 2018; 59 (4): 302 - 317
}

Key words: HPV; RT-QPCR; oncogenes; mRNA; E2; E6; E7.

\begin{abstract}
The human papilloma virus (HPV) belongs to a group of viruses with double-stranded DNA, with 35 genotypes capable of infecting the epithelium of skin surfaces through the body and mucous membranes of the ano-genital area. Genotype 16 is classified as a high-risk oncogenic HPV and has been identified more frequently in cervical-uterine infections and carcinomas. The objective proposed in this work was to evaluate the expression of viral mRNAs as indicators of progression of intraepithelial lesions (IEL), caused by HPV 16. We proceeded to the determination of the mRNA of the viral genes E2, E6, and E7 through the use of a polymerase chain reaction test with quantitative real time reverse transcriptase (RT-qPCR). HPV 16 was detected in $31.58 \%$ (12/38) of the total of patients; in low-grade lesions it was observed in $29.63 \%$ and in highgrade lesions, in $36.36 \%$ of the cases. The total quantified viral mRNA increased as the amount of oncogenic HPV present in the sample increased $\left(\mathrm{R}^{2}=0.51\right)$. A correlation $\left(\mathrm{R}^{2}=0.36\right)$ was found between the expression of the E7gene and the progression of the degree of the lesion. It was concluded that, the expression of mRNA of the viral genes E6 and E7 could be used in the future for the effective evaluation of the progression in the lesions of patients infected by HPV 16 in order to achieve the differentiation of the pre-cancerous lesions.
\end{abstract}

Recibido 04-09-2017 Aceptado 20-11-2018

\section{INTRODUCCIÓN}

El Virus Papiloma Humano (VPH) es un virus $\mathrm{ADN}$ de doble cadena perteneciente a la familia Papillomaviridae, que afecta de forma característica al epitelio de piel y mucosas, ya que su proceso de replicación causa alteraciones celulares de tipo proliferativo. Según el grado de atipia histológica de la lesión, estas alteraciones se categorizan como lesiones de bajo ǵrado (Condilomas) o lesiones de alto grado con desarrollo de neoplasias intraepiteliales que pueden evolucionar hasta Carcinoma in situ e invasivo.

Desde el punto de vista molecular, el VPH se divide en más de 100 genotipos, con unos 35 de localización ano-genital. Según el riesgo a sufrir transformación maligna, se clasifican como VPH de bajo o alto riesgo oncogénico. El VPH posee en su genoma ocho genes, de los cuales E6 y E7 codifican, en genotipos de alto riesgo, oncoproteínas con efectos a nivel de la división celular y la respuesta inmune, que con el tiempo son los causantes del desarrollo del cáncer uterino, una patología de elevada morbilidad y mortalidad en Venezuela y en el mundo $(1,2)$.

Recientes investigaciones han demostrado que el incremento de la carga viral se relaciona de manera directa con un aumento del crecimiento de las neoplasias; de igual forma se han demostrado relaciones similares entre la presencia y la cuantificación de los genes (1,3-5); cuando el VPH intracelular está fuera de los cromosomas, la expresión de los genes virales, también es responsable de 
los cambios que ocurren en la célula, para la producción de viriones infectantes. Además, se ha determinado que la proteína viral E2 está encargada de regular la producción de las oncoproteínas virales E6 y E7 que actúan sobre el ciclo celular; sin embargó, cuando el virus se integra al genoma celular, el gen de E2 queda excluido de la integración, por lo tanto, al perderse la regulación de esta forma, el crecimiento celular es incontrolado (6). De estos hallazgos, surge el interés de la evaluación conjunta de los ácidos ribonucleicos mensajeros (ARNm) de las oncoproteínas E7, E6 y de la proteína E2, debido a la relación existente entre ellos y la evolución neoplásica, la cual podría permitir el análisis del avance de las lesiones causadas por VPH de alto riesgo (6).

Investigaciones realizadas en México reportaron que las infecciones por VPH de bajo riesgo, no tienen posibilidades de ocasionar cáncer de cuello uterino, pero si estas son producidas por un VPH de alto riesgo, las posibilidades aumentan significativamente; por lo tanto, la técnica de biología molecular, conocida como Reacción en Cadena de la Polimerasa (PCR), es muy importante ya que permite la deteción y genotipificación viral del VPH genital causante de la infección (7).

En la actualidad, el diagnnóstico cérvicouterino de VPH, se realiza con la prueba de despistaje citológico microscópico de Papanicolaou (Pap) y la prueba de detección molecular del ADN del VPH por PCR. La prueba de VPH ADN es la única aprobada por la FDA (Administración de Drogas y Alimentos) de los Estados Unidos de América (8) y la Prueba Pap a pesar de ser una gran herramienta de cribado para la detección de lesiones precancerosas y cancerosas, no detecta al virus del VPH, sino los cambios citológicos producidos por la infección lítica (coilocitosis caracterizada por presencia de un halo claro citoplasmático) o lisogénica (agrandamiento e hipercromatismo nuclear con pérdida de la relación núcleo-citoplasma normal) del virus; su metodología es dependiente de la evaluación subjetiva, lo cual es una gran limitación, ya que no está relacionada directamente con el virus $(5,9)$.

En Venezuela la infección genital por VPH afecta comúnmente a parejas, observándose que un $70 \%$ de las personas lo ha adquirido por transmisión sexual. El hecho de que el hombre infectado puede no presentar ninguna sintomatología llamativa (solo el 40\% presenta síntomas), favorece la transmisión de la enfermedad sin el conocimiento de presentarla (10). En consecuencia, el VPH se convierte en un problema de salud pública ya que el $80 \%$ de la población portadora del virus no es consciente de su infección (10).

En una recopilación estadística realizada en Venezuela durante los años 2007 a 2011, se encontró que cada año fueron diagnosticados 3.685 casos de cáncer del cuello uterino, el cual representó un $57 \%$ de la incidencia del cáncer en el sexo femenino; en la misma recopilación, reportaron un total de 1.602 muertes a causa del cáncer de cuello uterino (11), lo cual se mantuvo al año siguiente, siendo reportadas 1.321 muertes en el anuario de mortalidad del año 2012 en Venezuela (2).

En el año 2001 se encontró que en Venezuela, como en otras partes del mundo, el genotipo relacionado con mayor frecuencia con lesiones ano-genitales pre-malignas y malignas, es el VPH-16 (10), el cual posee reconocidas propiedades oncogénicas; en esa misma investigación concluyeron que adicional a los criterios citológicos, histopatológicos y colposcópicos utilizados usualmente para el diagnóstico de la infección, se deberían realizar técnicas de biología molecular para la detección del virus.

Se ha demostrado en diversas investigaciones, que los pacientes que padecen carcinoma de células escamosas presentan una carga viral del VPH alta junto a una expresión positiva de los ARNm (ARN mensajeros) de las oncoproteínas E6 y E7; por el contrario, pacientes que tienen un mejor pronóstico son los que presentan una carga viral (ADN viral positivo) con ausencia del 
$\mathrm{ARNm}$, ya que es indicativo que el proceso de la oncogénesis no está ocurriendo activamente (12).

Con base en lo anterior, el objetivo de este estudio fue evaluar la expresión de los ARNm de genes virales como marcadores predictivos del avance de las lesiones producidas por VPH 16, mediante el uso de la técnica de biología molecular conocida como la Reacción en Cadena de la Polimerasa (PCR), para lograr de esta forma, acelerar el diagnóstico oportuno de las lesiones precancerosas, para que los pacientes reciban el tratamiento de manera precoz y así disminuir la progresión de las lesiones por este genotipo de virus (12).

\section{MATERIALES Y MÉTODOS}

\section{Muestras}

En la presente investigación fueron utilizadas muestras preservadas en el Laboratorio de Patología Molecular, Cátedra de Anatomía Patológica, Instituto Anatomopatológico José Antonio O'Daly, Escuela Luis Razetti, Facultad de Medicina de la Universidad Central de Venezuela (UCV), Caracas, Venezuela; una población total de 38 pacientes, provenientes de diversos lugares del país, 23 de sexo femenino y 15 masculinos, todos mayores de 18 años con diagnnóstico anatomopatológico (citológico e histológico) de VPH en conjunto con la presencia de lesiones epiteliales descritas según los estatutos del Sistema Bethesda (13). Este trabajo fue avalado por el Comité de Bioética de la Escuela de Bioanálisis de la UCV (CBEB).

Para la toma de muestra, a cada paciente le fue entregada la planilla de consentimiento informado previa explicación de la misma; adicionalmente, fue completada una planilla con la información relevante del paciente y las características de la lesión presente. La toma fue realizada por el médico tratante; en las mujeres por medio de un cepillado del cuello uterino y en los hombres por un raspado anal o peneal según la ubi- cación de la infección. La muestra fue colocada en un medio de transporte y llevada en un breve lapso de tiempo al Laboratorio de Patología Molecular; las biopsias, fijadas con Formaldehído al 10\% fueron embebidas en un bloque de parafina para posteriormente realizar la coloración de Papanicolaou y una porción de cada muestra fue preservada a $-70^{\circ} \mathrm{C}$ para su posterior uso en Biología Molecular.

\section{Procesamiento de las muestras de VPH}

Para cada procedimiento en el laboratorio, se esterilizó la Campana de Bioseguridad Clase II (Promega) por medio de luz ultravioleta durante 15 minutos; posteriormente, los reactivos conservados $\mathrm{a}-20^{\circ} \mathrm{C}$, fueron equilibrados a temperatura ambiente, protegidos de la luz solar directa y colocados en hielo para así mantener su estabilidad, de igual forma se hizo con las muestras, las cuales se encontraban conservadas a $-70^{\circ} \mathrm{C}$.

\section{Extracción del ADN a partir de \\ las muestras para la detección y genotipificación del VPH}

El contenido del medio de transporte fue transferido a un tubo de $1,5 \mathrm{~mL}$, el cepillo fue escurrido al máximo, siendo el escurrido aǵregado al tubo. La extracción del material genético fue realizada con el estuche QIAmp DNA kit N 51306 (QLAGEN) según el procedimiento descrito por el fabricante, todas las centrifugaciones fueron realizadas a 17.900 g, en una micro centrífuga Spectrafuge 24D de Labnet International. Finalizado el proceso las muestras fueron conservadas a $-70^{\circ} \mathrm{C}$ hasta su procesamiento (14).

\section{Detección y Genotipificación del virus de VPH}

El proceso de genotipificación consistió en una PCR multiplex anidada en dos pasos; en el primer paso se realizó una ampliación utilizando cebadores de consenso GP5+/ GP6+ y MY09/MY11 que reconocen secuencias comunes del Gen L1 en todos los VPH,

Vol. 59(4): 302 - 317, 2018 
esto permite la detección del genoma viral en la muestra $(15,16)$. Posteriormente se realizó la tipificación, consistente en una PCR multiplex anidada de 2 rondas programadas en un termociclador convencional TC-3000X. En la primera ronda se amplificó la región E6/E7, facilitando y mejorando los resultados en la segunda ronda, en la cual se utilizaron varios conjuntos de cebadores permitiendo la tipificación de 19 genotipos. Esta metodología no solo logra determinar el genotipo de VPH presente, también permite detectar infecciones por múltiples genotipos de VPH (coinfección) (15-17).

\section{Obtención de Patrones de los genes E7, E6 y E2 del VPH 16}

Los patrones de amplicones de los genes E7, E6 y E2 del VPH se obtuvieron a partir de las muestras con VPH 16. La mezcla maestra de todas las PCR convencionales fue preparada bajo condiciones establecidas por el protocolo del estuche de Go $\mathrm{Taq}^{\circledR}{ }^{\mathrm{qPCR}}$ Systems N A6001 (Promega).

La amplificación de la secuencia específica del gen E7 del VPH 16 se realizó por medio de la PCR convencional utilizando la pareja de cebadores y la programación estandarizados para el termociclador TC-3000X en $(1,16,17)$. En la amplificación de la secuencia específica del gen E6 del VPH 16, la pareja de cebadores utilizados y la programación del termociclador TC-3000X se realizó en base a trabajos consultados (15-17).

En la amplificación de la sección específica del gen E2 del VPH 16 la pareja de cebadores y la programación del termociclador TC-3000X fueron los mismos que el trabajo consultado de (16).

La comprobación de la amplificación fue realizada con un gel de Agarosa preparado al $2 \%$ con un buffer TAE al $0,5 \%$. El equipo utilizado para la corrida electroforética fue el Gel Electrofores SystemminiRunGE-100 BIOLR Technology COLIO, se usaron $8 \mu \mathrm{L}$ de muestra más $3 \mu \mathrm{L}$ de marcador. Para la visualización de las bandas de amplificación, se aǵregó Bromuro de Etidio $(10 \mathrm{mg} / \mathrm{mL})$ al gel de Agarosa $(2 \mu \mathrm{L})$ durante su preparación lo que facilitó la observación de los productos con el Transiluminador de luz ultravioleta (Uvitec). Las bandas esperadas para cada producto fueron las siguientes: VPH 16 E7: 115 pares de bases (pb); VPH 16 E6: 134 pb; VPH 16 E2: 149 pb; GAPDH: 230 pb, con cada electroforesis se utilizó un marcador de peso molecular de $100 \mathrm{pb}$ (Promega) $(1,15)$.

\section{Purificación de los patrones}

Cada patrón fue purificado por separado para la eliminación de elementos y contaminantes según las instrucciones establecidas por el fabricante del estuche de Purificación de PGR (QIAquick ${ }^{\circledR}$ PCR Purification Kit) $\mathrm{N}^{\circ}$ 28104.

La medición de la concentración de los patrones fue realizada con el uso de un Espectrofotómetro NAS-99, por medio del cociente $(260 / 280)$ se obtuvo un valor que permitió conocer si el filtrado presentaba proteínas o material degradado, los filtrados con cocientes $(260 / 280)>2$ fueron aceptados y los filtrados con un cociente $(260 / 280) \leq 1,9$ fueron descartados (14). La medición de cada patrón se realizó por triplicado para la obtención de un valor promediado, el cálculo de la concentración del ADN se realizó con la fórmula: donde la concentración $(\mathrm{ng} / \mu \mathrm{L})$ es dividida entre el producto de la longitud del producto $(\mathrm{pb})$ y el número de gramos de $\mathrm{ADN}$ de doble cadena presentes en un mol, todo multiplicado por el número de Avogadro, esta fórmula permitió convertir la concentración de cada patrón de $(\mathrm{g} / \mu \mathrm{L})$ a (\#de moléculas/ $\mu \mathrm{L})$ (18).

Fueron realizadas diluciones seriadas 1/10 del patrón de cada gen; se inició con $10^{9}$ \#moléculas/ $\mu \mathrm{L}$ hasta $10^{2}$ \#moléculas/ $\mu \mathrm{L}$, las diluciones fueron realizadas en tubos de 1,5 mL con agua destilada libre de nucleasas, se identificaron y separaron en alícuotas y fueron almacenadas a $-70^{\circ} \mathrm{C}$. 


\section{Realización de la Curva de Calibración para la PCR en tiempo real}

La mezcla maestra para la q-PCR (en tiempo real) se preparó en base al protocolo propuesto por el fabricante del estuche Go Taq $^{\circledR}$ qPCR Systems No A6001 (Promega), quedando los reactivos en el volumen final $(25 \mu \mathrm{L})$ en las siguientes concentraciones: Buffer $1 \mathrm{x}, \mathrm{MgCl}_{2} 3 \mathrm{mM}$, SYBR-Green $0,1 \mathrm{x}$, ROX 0,3x, dNTPs $0,25 \mathrm{mM}$, cebadores 0,2 $\mathrm{mM}$ cada uno (esta pareja de cebadores varió según la secuencia a amplificar), Taq Polimerasa $0,05 \mathrm{uL}$, templado (ADN) $(2 \mu \mathrm{L})$. Para lograr la cuantificación de los ARNm se realizaron curvas de calibración para cada gen, para lo cual se utilizaron los patrones de amplicones obtenidos en el laboratorio, a los cuales se les conocía su concentración en número (\#) de moléculas/ $\mu \mathrm{L}$.

Cada curva de calibración fue programada en el Termociclador en tiempo real 7500 de Applied Biosystems en una misma placa; se programaron los tiempos y temperaturas estandarizadas durante la obtención de los patrones de los genes de E7, E6 y E2: Desnaturalización $95^{\circ} \mathrm{C}$ x $15 \mathrm{~min} ; 40$ Ciclos $95^{\circ} \mathrm{C} \times 45 \mathrm{~s}, 55^{\circ} \mathrm{C}$ x $60 \mathrm{~s}, 72^{\circ} \mathrm{Cx} 45 \mathrm{~s}$; Curva de Disociación $60-95^{\circ} \mathrm{C}$ en un período continuo.

\section{Extracción del ARN a partir de las muestras para la cuantificación de los ARNm virales}

La extracción del ARN de las muestras fue realizada según lo establecido por el fabricante del estuche de Extracción de ARN viral (QLAquick ${ }^{\circledR}$ Viral RNA Kit) $\mathrm{N}^{\circ} 52906$ Qiagen. Todas las centrifugaciones fueron realizadas a $6.000 \mathrm{~g}$ en la micro centrífuga Spectrafuge 24D. Al finalizar, el tubo con el filtrado fue identificado y almacenado en un congelador de temperatura ultra baja marca Il Shin Bio Base $\left(a-70^{\circ} \mathrm{C}\right)$ hasta el momento de su procesamiento.

\section{Transcripción reversa de PCR en Tiempo Real cuantitativa (RT-qPCR)}

La transcripción reversa de $\mathrm{PGR}$ en Tiempo Real cuantitativa (RT-qPCR) de un paso se realizó en el Termociclador en tiempo real 7500 de Applied Biosystems; la mezcla de reactivos se realizó según las instrucciones del fabricante del estuche Gotaq $^{\circledR}$ 1-Step RT-qPCR Systems No A6020 (Promega), quedando las concentraciones: Gotaq ${ }^{\circledR} \mathrm{qPCR}$ Master Mix (1x), GoSeript ${ }^{\mathrm{rx}}$ RT Mix for 1-Step RT-qPCR, $(0,4 \mu \mathrm{L})$, agua libre de Nucleasas $(1,6 \mu \mathrm{L})$, cebadores $(1,25 \mathrm{mM}$ cada uno), muestra (ARN) $(4 \mu \mathrm{L})$. Los tiempos, ciclos y temperaturas programados en el Termociclador en tiempo real 7500 de Applied Biosystems para la RT-qPCR fueron los mismos estandarizados para las curvas de calibración de los ARNm de E7, E6 y E2: Estadio Inicial $\left[37^{\circ} \mathrm{C} \times 15 \mathrm{~min}\right.$ ]; Desnaturalización $95^{\circ} \mathrm{C} \times 15 \mathrm{~min}$; 40 Ciclos $\left(95^{\circ} \mathrm{C} \times 45 \mathrm{~s}\right.$, $55^{\circ} \mathrm{C} \times 60 \mathrm{~s}, 72^{\circ} \mathrm{C} \times 45 \mathrm{~s}$ ); Curva de Disociación $60-95^{\circ} \mathrm{C}$ en un período continuo.

$\mathrm{El}$ control de calidad de todas las extracciones se realizó con una PCR en tiempo real para el ARNm del gen constitutivo GADPH, utilizando el Cebador directo: 5'-ACG GAT TTG GTC GTA TTG GG-3' y el Cebador inverso: (5'-TGA TTT TGG AGG GAT CTC GC-3' y sus tiempos estandarizados para el gen; los controles negativos fueron procesados por triplicado y cada muestra fue procesada por duplicado.

\section{Técnica del análisis de datos}

La información recopilada de los resultados obtenidos durante la investigación, se analizó con el Programa estadístico IBM SPSS Statistics 22 para Windows; para el cálculo del porcentaje, coeficiente de correlación, correlación de Pearson, regresión lineal, y la distribución de Fisher.

\section{RESULTADOS}

Al evaluar los datos de cada paciente se obtuvo un promedio general de 30,50 \pm 10,01 años, siendo la media de edad para las mujeres establecida en 31,34 $\pm 10,27$ años y para los hombres la media fue de $28,88 \pm$ 9,47 años.

En los pacientes estudiados, las lesiones de bajo grado estuvieron presentes en un 
$71,05 \%$, mientras que las de alto grado estuvieron presentes en el 28,95\%. La frecuencia de coinfecciones por más de un genotipo de VPH fue de un $76,32 \%$.

\section{Detección y Tipificación viral del VPH}

Todas las muestras arrojaron un resultado positivo para la presencia del VPH. La frecuencia de los genotipos de VPH se distribuyó como se expone en la Tabla I, observándose que en el total de muestras prevaleció el VPH 6/11 de bajo riesgo oncogénico con un 44,74\%, seguido del VPH 42 con 39,47\%; mientras que entre los VPH de alto riesgo los más frecuentes fueron el VPH 16 con 31,58\% seguido del VPH 18 con un 26,32\%.
En lesiones de bajo grado el genotipo VPH 6/11 se encontró en $\mathbf{5 5 , 5 5 \%}$ de las muestras, seguido de los VPH 42, 16 y 18 con 29,63\%; por otro lado, en lesiones de alto grado el VPH 16 prevaleció junto al VPH 51 con $36,36 \%$, mientras que los VPH 18, 31 y 33 aparecieron en un 18,18\%.

\section{Cuantificación de los ARNm de las proteínas virales $\mathrm{E} 7, \mathrm{E} 6$ y E2}

La cuantificación de los ARN mensajeros solo fue realizada en muestras donde fue detectado el VPH 16, las cuales fueron 12 de 38 muestras, $31,56 \%$ del total evaluado. En la Fig. 1, se pueden apreciar las amplificaciones registradas durante el proceso de la RT-

TABLA I

TIPIFICACIÓN VIRAL Y CLASIFICACIÓN ANATOMOPATOLÓGICA DE LOS PACIENTES ESTUDIADOS

\begin{tabular}{|c|c|c|c|}
\hline \multirow{2}{*}{ Tipo de VPH } & \multicolumn{2}{|c|}{ Grado de lesión } & \multirow{2}{*}{ En todas las lesiones histológica } \\
\hline & Bajo grado & Alto grado & \\
\hline \multicolumn{4}{|l|}{ Bajo riesgo } \\
\hline $6 / 11$ & $55,55 \%(15 / 27)$ & $9,09 \%(1 / 11)$ & $44,74 \%(17 / 38)$ \\
\hline 42 & $29,63 \%(8 / 27)$ & $63,63 \%(7 / 11)$ & $39,47(15 / 38)$ \\
\hline 43 & $14,81 \%(4 / 27)$ & $18,18 \%(2 / 11)$ & $15,79 \%(6 / 38)$ \\
\hline 44 & $11,11 \%(3 / 27)$ & $9,09 \%(1 / 11)$ & $10,53 \%(4 / 38)$ \\
\hline \multicolumn{4}{|l|}{ Alto riesgo } \\
\hline 16 & $29,63 \%(8 / 27)$ & $36,36 \%(4 / 11)$ & $31,58 \%(12 / 38)$ \\
\hline 18 & $29,63 \%(8 / 27)$ & $18,18 \%(2 / 11)$ & $26,32 \%(10 / 38)$ \\
\hline 31 & $11,11 \%(3 / 27)$ & $18,18 \%(2 / 11)$ & $13,16 \%(5 / 38)$ \\
\hline 33 & $7,41 \%(2 / 27)$ & $18,18 \%(2 / 11)$ & $10,52 \%(4 / 38)$ \\
\hline 35 & $18,52 \%(5 / 27)$ & $18,18 \%(2 / 11)$ & $18,42 \%(7 / 38)$ \\
\hline 39 & $18,52 \%(5 / 27)$ & $18,18 \%(2 / 11)$ & $18,42 \%(7 / 38)$ \\
\hline 45 & $11,11 \%(3 / 27)$ & $18,18 \%(2 / 11)$ & $13,16 \%(5 / 38)$ \\
\hline 51 & $18,52 \%(5 / 27)$ & $36,36 \%(4 / 11)$ & $23,68 \%(9 / 38)$ \\
\hline 52 & $3,70 \%(1 / 27)$ & $9,09 \%(1 / 11)$ & $5,26 \%(2 / 38)$ \\
\hline 56 & $11,11 \%(3 / 27)$ & $18,18 \%(2 / 11)$ & $13,16 \%(5 / 38)$ \\
\hline 58 & $7,41 \%(2 / 27)$ & $27,27 \%(3 / 11)$ & $13,16 \%(5 / 38)$ \\
\hline 59 & $7,41 \%(2 / 27)$ & $9,09 \%(1 / 11)$ & $7,89 \%(3 / 38)$ \\
\hline 66 & $7,41 \%(2 / 27)$ & $18,18 \%(2 / 11)$ & $10,53 \%(4 / 38)$ \\
\hline 68 & $11,11 \%(3 / 27)$ & $9,09 \%(1 / 11)$ & $10,53 \%(4 / 38)$ \\
\hline
\end{tabular}



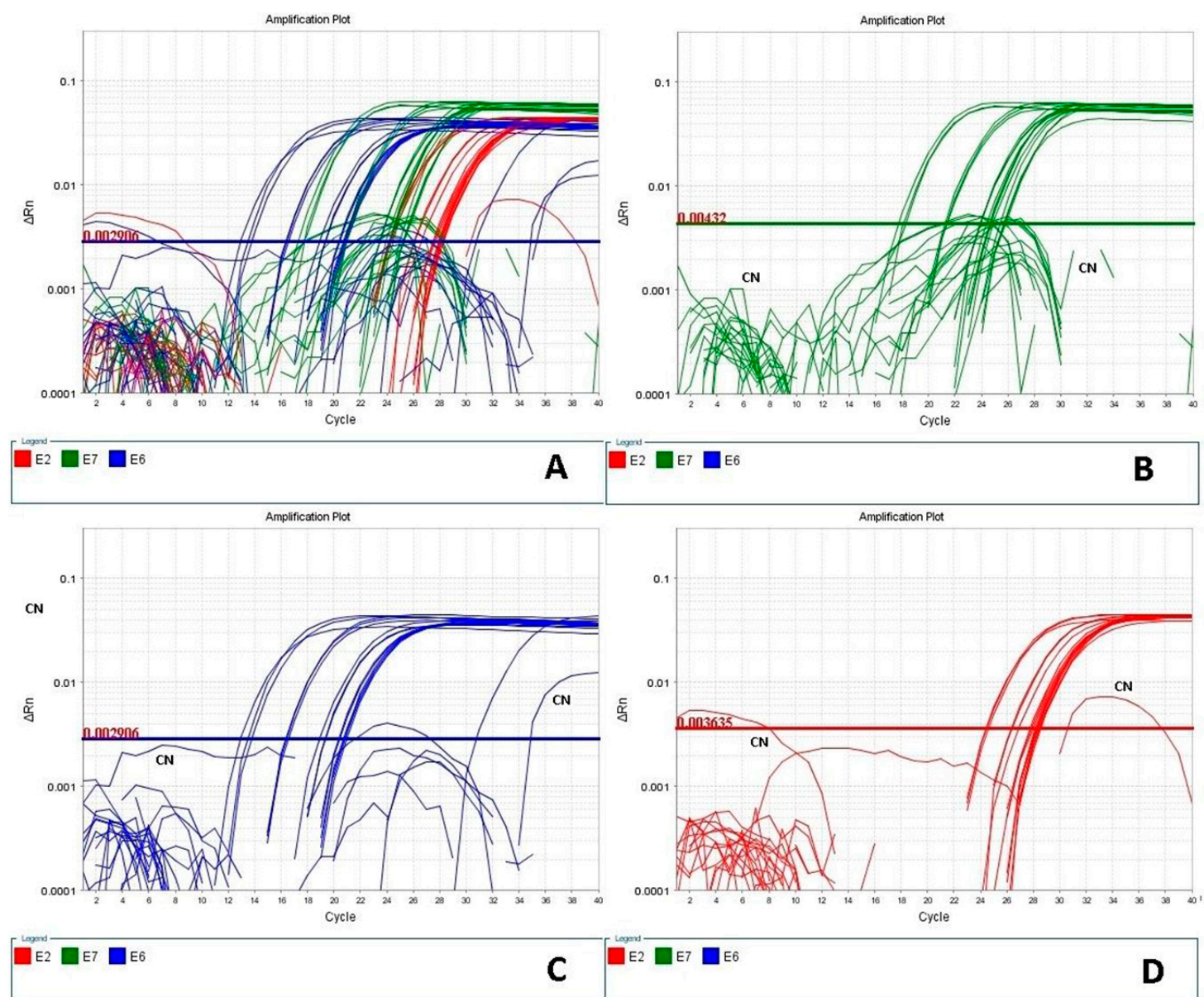

Fig. 1. (A) Amplificación de los ARNm por medio de la RT-PCRq en tiempo real. (B) Gráfica de la amplificación de los ARNm de E7, en ella se aprecia mejor la curva de calibración, los controles negativos (CN) y las muestras de los pacientes, así como su correspondiente Umbral = 0,00432. (C) Gráfica de la amplificación de los ARNm de E6, la curva de calibración, controles negativos (CN) y las muestras evaluadas, Umbral=0,002906. (D) Gráfica de la amplificación de los ARNm de E2, se muestra la curva de calibración, controles negativos (CN) y las muestras de los pacientes, Umbral = 0,003635.

PCRq, en ellas están presentes: las curvas de calibración de E2, E6, E7, los controles negativos y todas las muestras evaluadas para $\operatorname{los} 3 \mathrm{ARNm}$; se aclara, que los controles negativos se encuentran por debajo del umbral o después del ciclo 30, criterio que los valida como negativos. La representación gráfica de las curvas de calibración y la ubicación de los resultados de las muestras evaluadas en cada uno de los ARNm evaluados se muestran en las Figs. 2, 3 y 4.

Las curvas de calibración mostraron las siguientes pendientes: Gen E7 $(-2,22)$, Gen E6 $(-3,86)$, Gen E2 $(-3,68)$ con los coeficien- tes de correlación $\left(\mathrm{R}^{2}\right)$ : Gen E7 $(0,98)$, Gen E6 $(0,99)$, Gen E2 $(0,99)$. En la curva de disociación se obtuvieron temperaturas similares: para $\mathrm{E} 7\left(78,33^{\circ} \mathrm{C}\right)$; para E6 $\left(76,39^{\circ} \mathrm{C}\right)$ y para E2 $\left(72,76^{\circ} \mathrm{C}\right)$ (Fig. 5).

Como comprobación de las amplificaciones de cada ARNm, posterior a la PCR en tiempo real se realizaron electroforesis en gel de agarosa al 2\% para la observación de los productos amplificados junto al peso molecular (Promega) escalado en 100 pb, observando la presencia de las bandas específicas y únicas: gen GAPDH (230 pb), gen E7 (115 pb), gen E6 (134 pb), gen E2 (149 pb). 


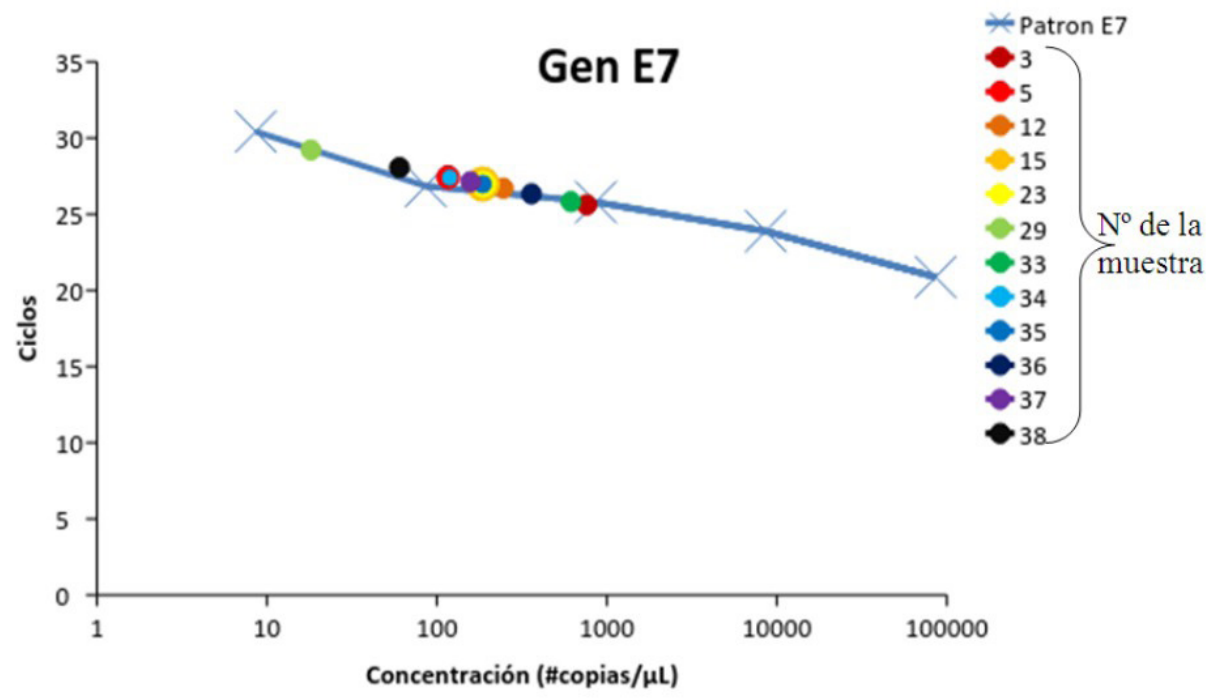

Fig. 2. Curva de Calibración para el ARNm del Gen E7. La pendiente de la curva de calibración para el Gen E7 es de -2,22, su coeficiente de correlación es $\mathrm{R}^{2}=0,98$; los Ct obtenidos están dentro del rango aceptable $(>8 \mathrm{y}<35)$ además puede observarse que todas las muestras se mantienen dentro de la linealidad del método.



Fig. 3. Curva de Calibración para el ARNm del Gen E6. Pendiente = -3,86; Coeficiente de correlación $\mathrm{R}^{2}=$ 0,99 indicando una excelente relación entre los datos obtenidos en los puntos realizados en la curva de calibración; los Ct se mantuvieron en el rango esperado entre el ciclo 8 y el ciclo 35; solamente una muestra $\left(\mathrm{N}^{\circ} 12\right)$ se salió de la linealidad de la metodología con una concentración más baja de lo esperado. 


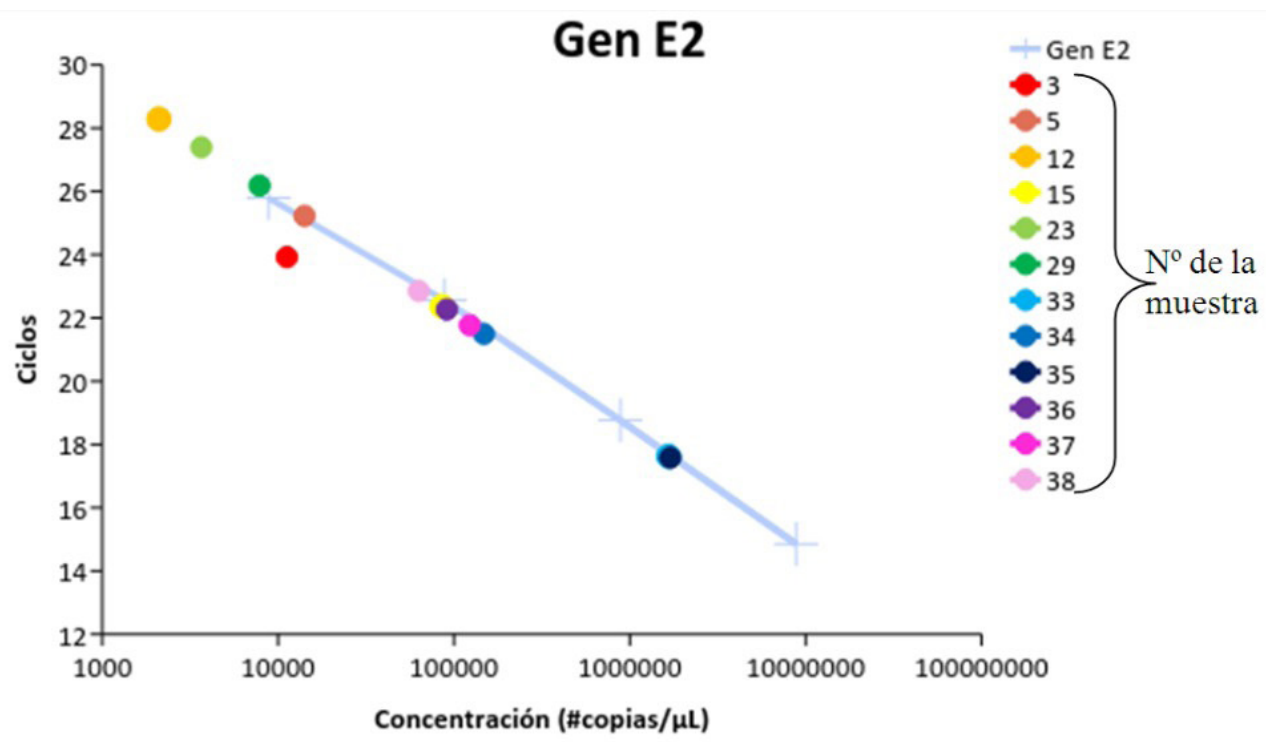

Fig. 4. Curva de Calibración para el ARNm del Gen E2. Presentando una Pendiente de -3,68 demuestra que hubo un proceso óptimo en la amplificación de la secuencia en el patrón utilizado; la relación entre el descenso de la concentración y el incremento del Ct fue el ideal $\mathrm{R}^{2}=0,99$; en esta curva de calibración fueron tres muestras ( $\mathrm{N}^{\circ} 12,23$ y 29) las que estuvieron fuera de la linealidad del método por poseer poca cantidad del ARNm del Gen E2.

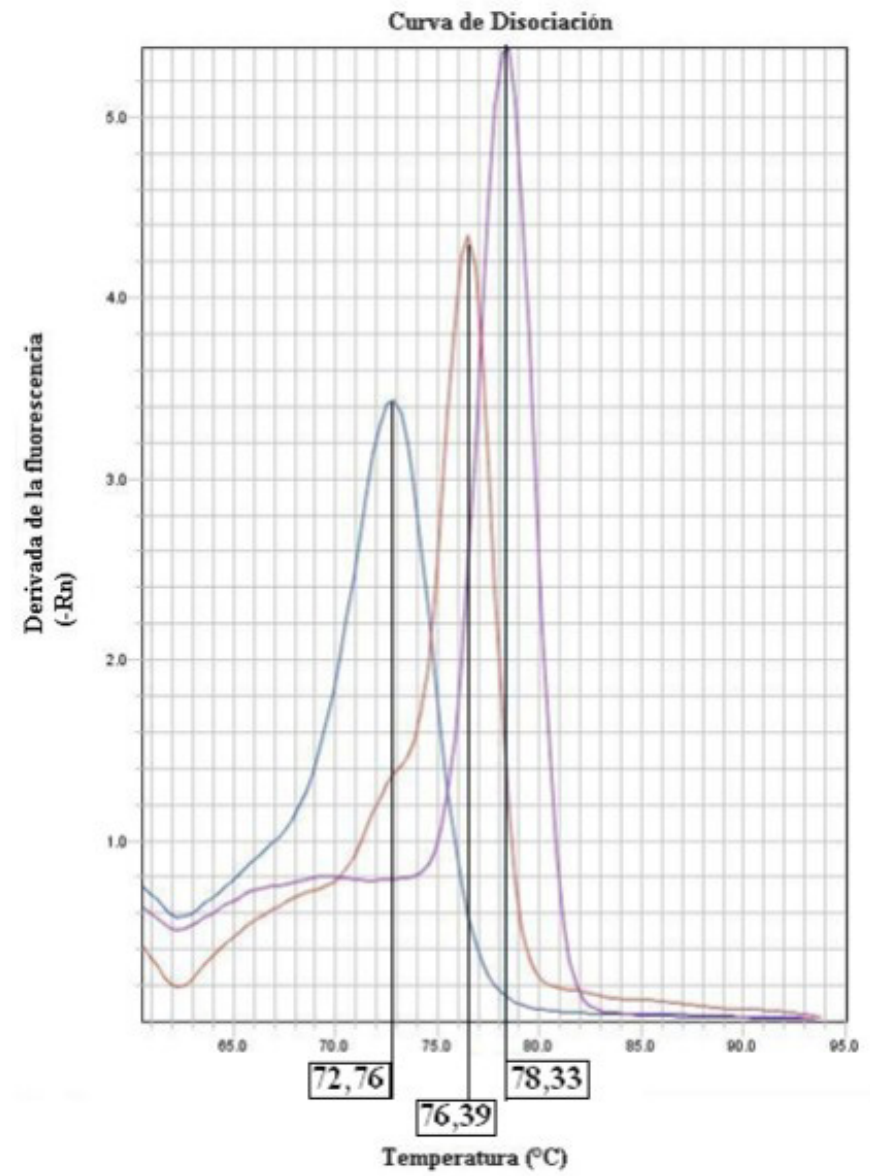

Fig. 5. Curva de Disociación de los productos amplificados. Se presenta los puntos máximos de fluorescencia obtenidos finalizadas las PCR en tiempo real durante el proceso de Disociación, de cada gen estudiado, Gen E7 $78,33^{\circ} \mathrm{C}$, Gen E6 $76,39^{\circ} \mathrm{C}$, Gen E2 $72,76^{\circ} \mathrm{C}$; siendo estos valores cercanos a los esperados, de igual forma se observaron los picos de fluorescencia únicos en los patrones y muestras evaluadas confirmando la ausencia de contaminaciones en el proceso.

Vol. 59(4): 302 - 317, 2018 
Los resultados obtenidos a partir de las curvas de calibración se muestran en la Tabla II, donde el ARNm de cada gen se expresa en \#copias/ $\mu \mathrm{L}$. En las curvas de los genes E6 y E2 se observa que en algunas muestras $(12,23$ y 29) los valores del Ct se mantuvieron por debajo de la linealidad del método, siendo indicativo de la poca cantidad de $\mathrm{ARNm}$ presente en la muestra; por lo tanto, las cantidades de ARNm obtenidas en los cálculos no son confiables, por ende, fueron excluidos de los análisis.

En la Fig. 6 se presenta el promedio de ARNm del gen E7 presente en las muestras, puede observarse el incremento de la expresión del gen viral E7 al aumentar el grado de la lesión que presentaba el paciente $\left(R^{2}=0,36\right)$.

\section{DISGUSIÓN}

Al igual que otras investigaciones que sugieren que la infección por VPH ocurre durante la etapa de mayor actividad sexual, el promedio de edad de los pacientes coincidió con los promedios establecidos para hombres y mujeres infectados con VPH, en esas edades una gran cantidad de hombres y mujeres jóvenes no se realizan revisiones periódicas, lo que explica la aparición de lesiones, incluyendo las de alto grado, alrededor de los 30 años $(10,19,21)$.

Fue notable la frecuencia de coinfecciones por más de un genotipo de VPH; las coinfecciones resultan en un problema para el paciente, ya que diversos estudios, así como el presente, han demostrado que la

TABLA II

GUANTIFICACIÓN DE LOS ARNm DE LAS ONCOPROTEÍNAS VIRALES E7, E6, E2 EN MUESTRAS DE PACIENTES INFECTADOS CON VPH 16.

\begin{tabular}{|c|c|c|c|c|c|}
\hline Paciente & Tipo de lesión & $\begin{array}{r}A R N m E 7 \\
{[\# \text { copias } / \mu \mathrm{L}]}\end{array}$ & $\begin{array}{r}A R N m \text { E6 } \\
{[\# \text { copias } / \mu \mathrm{L}]}\end{array}$ & $\begin{array}{r}A R N m E 2 \\
{[\# \text { copias } / \mu \mathrm{L}]}\end{array}$ & $\begin{array}{c}\text { ARNm Total } \\
{[\# \text { copias } / \mu \mathrm{L}]}\end{array}$ \\
\hline 3 & Lesión genital externa & 760,993 & $194.984,46$ & $11.220,18$ & $206.965,64$ \\
\hline 5 & $\begin{array}{r}\text { Neoplasia Intraepitelial } \\
\text { Peneal I }\end{array}$ & 116,211 & $30.902,95$ & $14.125,38$ & $45.144,54$ \\
\hline 12 & $\begin{array}{l}\text { Verrugas en labios } \\
\text { mayores y menores }\end{array}$ & 245,668 & $\approx$ & $\% *$ & $* *$ \\
\hline 15 & $\begin{array}{r}\text { Lesión Intraepitelial } \\
\text { Cervical II }\end{array}$ & 185,419 & $390.484,71$ & $85.776,75$ & $476.446,89$ \\
\hline 23 & $\begin{array}{r}\text { Lesión escamosa } \\
\text { en Recto }\end{array}$ & 187,354 & $35.450,65$ & $\because *$ & ** \\
\hline 29 & Úlcera genital & 18,138 & $75.906,66$ & $* *$ & $* *$ \\
\hline 33 & $\begin{array}{r}\text { Neoplasia Intraepitelial } \\
\text { Anal II }\end{array}$ & 613,824 & $6.606 .934,48$ & $1.659 .586,91$ & $8.267 .135,21$ \\
\hline 34 & Cambios por VPH & 118,896 & $69.183,09$ & $147.910,84$ & $217.212,83$ \\
\hline 35 & $\begin{array}{r}\text { Neoplasia Intraepitelial } \\
\text { Anal I }\end{array}$ & 185,804 & $11.481 .536,21$ & $1.698 .243,65$ & $13.179 .965,67$ \\
\hline 36 & Cambios por VPH & 359,982 & $263.026,79$ & $91.201,08$ & $354.587,86$ \\
\hline 37 & $\begin{array}{l}\text { Sin evidencias } \\
\text { de malignidad }\end{array}$ & 157,529 & $1.412 .537,54$ & $123.026,88$ & $1.535 .721,95$ \\
\hline 38 & Células normales & 60,169 & $48.977,88$ & $63.095,73$ & $112.133,79$ \\
\hline
\end{tabular}

(**): Valores fuera de la linealidad del método. 


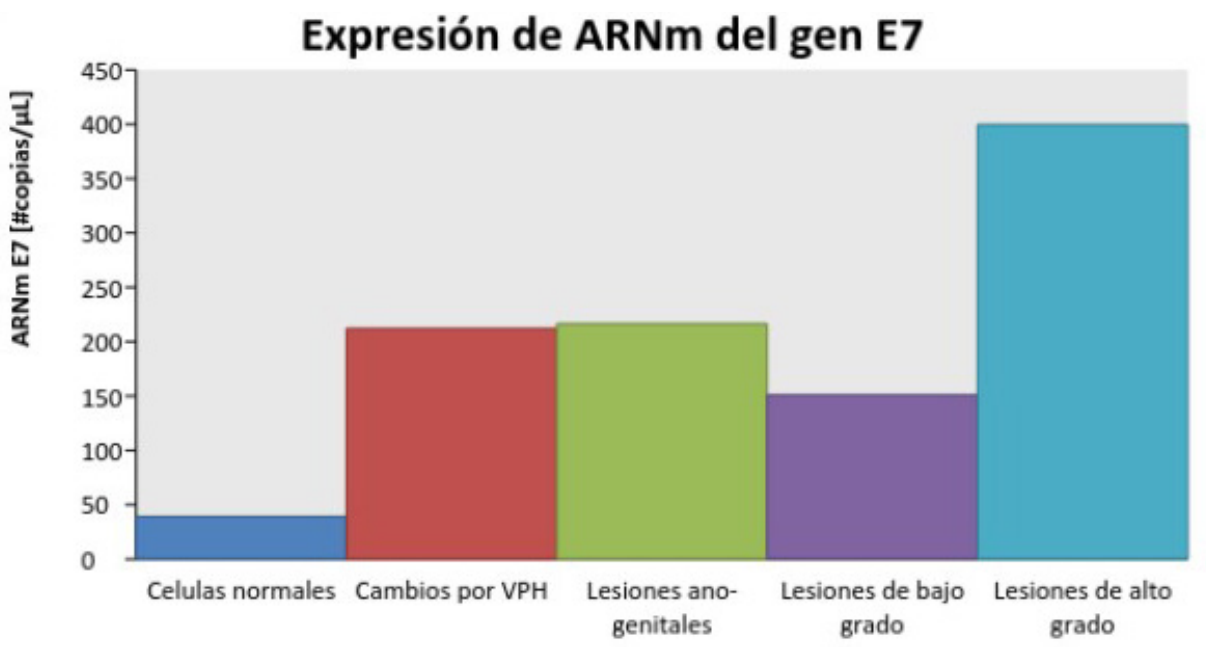

Fig. 6. Promedio de las cuantificaciones de ARNm del gen E7 en pacientes estudiados. Fueron promediados los valores obtenidos en las muestras, observándose de manera clara y precisa la ǵran diferencia entre la cantidad de ARNm del Gen E7 presentes en muestras de bajo ǵrado y las muestras que presentaban lesiones de alto grado (Precancerosas); demostrándose que la cuantificación del ARNm podrá tener una aplicación clínica para el diaǵnóstico y tratamiento temprano de las lesiones Pre cancerígenas.

presencia de diversos genotipos sobre todo los de alto riesgo, implica un incremento de la posibilidad de desarrollar cáncer (7). En pacientes con lesiones histológicas de bajo grado fue descubierto que la infección era con genotipos de alto riesgo, lo cual puede sugerir que esas lesiones pueden progresar a lesiones de alto grado y posteriormente a cáncer, como se han observado en otros estudios (22).

En lesiones de bajo grado el genotipo más frecuente fue el VPH 6/11, seguido de los VPH 42, 16 y 18, por otro lado, en lesiones de alto grado el VPH 16 prevaleció junto al VPH 51, mientras que los VPH 18, 31 y 33 estuvieron presentes con menor frecuencia; estos resultados coinciden con datos recopilados en Venezuela y a nivel mundial, demostrando que la permanencia de VPH de alto riesgo oncológíico está relacionada con el avance de las lesiones $(10,19,23)$. Se puede concluir que existe una prevalencia alta del VPH 16 entre los genotipos de alto riesgo en los pacientes, concordando con estudios anteriores en el país, del mismo modo se observó el incremento de la prevalencia del VPH 51 por encima del VPH 18 el cual concuerda con estudios epidemiológicos recientes (18).

Las curvas de calibración, arrojaron pendientes cercanas a $-3,3$ indicando que el proceso fue óptimo; los coeficientes de correlación $\left(\mathrm{R}^{2}\right)$ fueron excelentes, ya que lo ideal es un $\mathrm{R}^{2}>0,99$, estableciendo una relación directa entre los valores; y por último, los valores del Ciclo de Umbral $\left(\mathrm{C}_{\mathrm{t}}\right)$ se mantuvieron entre $>8 \mathrm{y}<35$, esto se tomó en cuenta ya que cuando el $\mathrm{C}_{\mathrm{t}}<8$ es indicativo de la existencia de mucho templado (ADN/ ARN) en la mezcla de reacción, y cuando el $\mathrm{C}_{\mathrm{t}}>35$ indica que el templado es escaso, esto causa en ambos casos el incremento de la desviación estándar.

Finalizada la RT-qPCR en tiempo real fueron revisadas las curvas de disociación de los patrones y las muestras evaluadas, y se observaron picos únicos de fluorescencia lo cual confirmó la ausencia de la contaminación durante el proceso.

$\mathrm{Al}$ evaluar la relación entre la expresión del gen E2 con la expresión del gen transformante E7 se observó muy poca relación 
entre ellos $\left(R^{2}=0,29\right)$, coincidiendo con la poca relación que se ha presentado en diversas investigaciones, en las cuales, incluso se ha observado una relación inversa entre la expresión de los genes transformantes y la expresión del gen E2, ya que este último tiende a quedar excluido al progresar la lesión y el genoma del VPH es integrado al genoma de la célula (24-26).

La expresión del gen transformante E6 aumentó con respecto a la del gen E7 con un buen grado de correlación, esto demuestra una relación entre la expresión de los genes transformantes E6 y E7 y el progreso de la lesión, ya que, al incrementarse el tipo de lesión, la expresión de los ARNm de los genes aumentaba proporcionalmente; este resultado concuerda con investigaciones de la presencia de estos $\mathrm{ARNm}$ en la progresión oncogénica de las lesiones $(1,3,24)$. ). Los resultados obtenidos también fueron analizados con la correlación de Pearson, obteniéndose valores de correlación similares a los obtenidos con los cálculos del coeficiente de correlación: correlación positiva $\rho=$ 0,23 entre la expresión de los ARNm de E7 y E2, y correlación positiva $\rho=0,18$ entre la expresión de los ARNm de E6 y E7.

Con respecto al total de $\mathrm{ARNm}$ de los genes virales se observó que a mayor cantidad de genotipos oncogénicos fue mayor la cantidad del ARNm presente, este resultado coincidió con los presentados en investigaciones dirigidas a relacionar la presencia de los ARNm de los genes transformantes E6 y E7 con el avance de la lesión $(12,25)$, respaldando el hecho que al aumentar la actividad del VPH posterior a su integración en el genoma celular, se produce un incremento de la expresión de estos genes virales, llevando al progreso de la lesión y a la transformación a un estadio de mayor grado de desdiferenciación. También se hace la aclaratoria que en otro estudio que utilizó las mismas secuencias en los cebadores para la amplificación del ARNm de los genes E2 y E6, encontraron una amplificación inespecífica al modificar los tiempos y temperaturas utilizadas durante la extensión en el proceso de PCR en tiempo real (23), comentamos esto ya que los tiempos y temperaturas de la PCR en tiempo real fueron modificados y es posible que un pequeño incremento no significativo en la cuantificación del ARN en las muestras, sea por la amplificación de las secuencias de ARN inespecíficas correspondientes a otros genotipos de VPH que estaban presentes en las muestras.

$\mathrm{Al}$ observar el incremento en las cantidades del ARNm del gen E7, se puede decir que la evaluación de la expresión de los ARNm podría ser utilizada en el estudio de los pacientes con lesiones por VPH, siempre y cuando se hagan los avances correspondientes para establecer criterios diaǵnósticos y la reducción de costos que permita una aplicación clínica de la cuantificación de los ARNm virales (27).

La expresión de los ARNm virales del VPH podría ser utilizada en la evaluación de las lesiones en pacientes, ya que como se observó en este estudio su cuantificación permite establecer una diferencia entre lesiones simples (de bajo grado) y las lesiones pre-cancerosas (de alto grado). Hasta donde sabemos estos estudios de los genes transformantes del VPH 16 no se han realizado en Venezuela y por lo tanto no existe una base de datos a la cual se puedan comparar estos resultados.

Pacientes que ya hayan recibido la vacuna contra el VPH o que presenten indicios de un proceso neoplásico por este virus, podrían ser evaluados para lograr reducir las consecuencias de las infecciones por VPH, con aumento de los diagnósticos oportunos por medio de las técnicas de biología molecular como la PCR (28). En los pacientes post-tratados, los ensayos basados en la detección del ADN viral llevan la pauta en la actualidad, sin embargó, carecen de una sensibilidad suficiente que permita discernir entre una infección nueva o una persistente (28-30); por ello, si la cuantificación de los ARNm se desea utilizar para el control 
de los pacientes, no solo es importante que la prueba posea una gran sensibilidad analítica, tiene además que tener sensibilidad a nivel clínico, y esta solo se logra evaluando a los pacientes indicados, es decir, aquellos que reúnan criterios establecidos (clínicos y epidemiológicos), ya que a partir de los resultados, los encargados del tratamiento tomarán la decisión de la conducta a seguir en el paciente (31).

En el año 2012 varias sociedades: American Cancer Society (ACS), American Society for Colposcopy and Cervical Pathology (ASCCP) y la American Society for Clinical Pathology (ASCP), concretaron diversos parámetros para la evaluación de pacientes, explicando que las mujeres jóvenes deberían realizarse una citología cada tres años, sin la necesidad de la detección del VPH por PCR, tomando en cuenta que muchas de las lesiones que pudieran presentar se deberán a VPHs de bajo riesgo los cuales no progresan a lesiones pre-cancerosas. Las mujeres mayores de 30 años, deberán realizarse la citología de forma conjunta a la detección del VPH por procedimiento de PCR en períodos de cada cinco años (27). Aquí tendría gran utilidad la cuantificación de estos ARNm virales, ya que aplicando estos parámetros se podrá lograr una mejor sensibilidad en cada caso en comparación a la simple detección del ADN del VPH oncogénico, lo que agilizará el diaǵnóstico y tratamiento efectivo de las lesiones de alto grado (HSIL) (30); también es necesario realizar otras investigaciones enfocadas en el estudio de las proteínas virales E6 y E7, ya que el aumento de ellas es la verdadera causa de los cambios celulares. De esta forma se logrará afianzar un buen marcador de progiresión (32-33).

\section{REFERENCIAS}

1. Babawale M, Seth R, Christian A, Al-Utayem W, Narula R, Jenkins D. Histological analysis of eervical intraepithelial neoplasia. Methods Mol Med 2005; 119: 41-48.
2. Ministerio del Poder Popular para la Salud. Anuario de Mortalidad 2012 República Bolivariana de Venezuela. 2014 [cited 2017 Jul 6]; 233. Disponible: http://www.ovsalud. org/descargas/publicaciones/documentosoficiales/Anuario-Mortalidad-2012.pdf.

3. Scheurer ME, Dillon LM, Chen Z, Follen M, Adler-Storthz K. Absolute quantitative real-time polymerase chain reaction for the measurement of human papillomavirus E7 mRNA in cervical cytobrush specimens. Infect Agent Cancer 2007; 2: 8. Doi: 101186/1750-9378-2-8.

4. Hernández-Arteaga S, López-Revilla R. Ultrasensitive quantitation of human papillomavirus type $16 \mathrm{E} 6$ oncogene sequences by nested real time PCR. Infect Agent Cancer 2010; 5: 9. Doi: 10.1186/1750-9378-5-9.

5. Schmitt M, Depuydt C, Benoy I, Bogers J, Antoine J, Pawlita M, Arbynet M. Viral load of high-risk human papillomaviruses as reliable clinical predictor for the presence of eervical lesions. Cancer Epidemiol Biomarkers Prev 2013; 22: 406- 414.

6. García-Tamayo J, Molina J, Blasco-Olaetxea E. El virus del papiloma humano y el cáncer cervical. Una revisión de la historia actualizada sobre la investigación del cáncer del cuello uterino en Venezuela. Invest Clin 2010; 51(2): 193 - 208.

7. Rojo RG. Utilidad de las téenicas moleculares de detección de VPH en el control y prevención del cáncer cervicouterino. Archivos Médicos de Actualización en Tracto Genital Inferior 2011; 3(5): 16-23.

8. Bazán F, Posso M, Gutiérrez C. Conocimientos, actitudes y prácticas sobre la prueba de Papanicolaou. An Fac Med Lima 2007; 68(1): 47-54.

9. Lizano-Soberón M, Carrillo-García $A$, Contreras-Paredes A. Infección por virus del Papiloma Humano: epidemiología, historia natural y carcinogénesis. Cancerologia 2009; 4: 205-216.

10. Pulido AM, Angulo AG, Ávila M, Cavazza ME, Crespo L, Vásquez W, Súnico N. Infección por el virus de papiloma humano (VPH) en mujeres: Características epidemiológicas, clínicas y patológicas. Dermatología Venez 2011; 49: 3-4.

11. Pardo C, Cendales R. Supervivencia de pacientes con cáncer de cuello uterino trata-

Vol. 59(4): 302 - 317, 2018 
das en el Instituto Nacional de Cancerología. Biomédica 2009; 29: 437-447.

12. Jung AC, Briolat $J$, Millon $R$, de RA, Rickman D, Thomas E, Abecassis J, Clavel C, Wasylyk B. Biological and clinical relevance of transcriptionally active human papillomavirus (HPV) infection in oropharynx squamous cell carcinoma. Int $\mathrm{J}$ Cancer 2010; 126(8): 1882-1894.

13. Pérez JFB, Robelo CPC, Rosales KLG, Velásquez SMG. Pruebas de detección del cáncer cervicouterino asociado al Virus del Papiloma Humano (VPH). Rev Univ y Ciencia, UNAN-Managua 2015; 8(12): 34-44.

14. Pinto A Di, Forte V, Guastadisegni MC, Martino C, Schena FP, Tantillo G. A comparison of DNA extraction methods for food analysis. Food Control 2007; 18: 76-80.

15. Shafiei Jandaghi NZ, Shahsiah R, Jahanzad I, Yavarian J. Detection and typing of human papilloma viruses by nested multiplex polymerase chain reaction assay in cervical cancer. Jundishapur J Microbiol 2015; 8(12): e26441.

16. Michelli E, Téllez L, Mendoza J-A, Noguera M-E, Milano M, Vera R. Amplification of human papillomavirus early genes for detection of nine genotypes in Venezuelan women. Invest Clin 2013; 54(4): 392-405.

17. Sotlar K, Diemer D, Dethleffs A, Hack Y, Stubner A, Vollmer N, Menton S, Menton M, Dietz K, Wallwiener D, Kandolf R, Bültmann B. Detection and typing of human papillomavirus by E6 nested multiplex PCR. J Clin Microbiol 2004; 42(7): 3176-3184.

18. Laurell H, Iacovoni JS, Abot A, Svec D, Maoret JJ, Arnal JF, Kubista M. Correction of RT-qPCR data for genomic DNA-derived signals with Valid Prime. Nucleic Acids Res 2012; 40(7): e51.

19. Castellsague $X$, Bruni L, Alemany L, Diaz M, De Sanjosé S, Bosch FX. The epidemiology of eervical cancer. In: HPV and Cervical Cancer: Achievements in Prevention and Future Prospects 2012; 40(7): e51.

20. Seaman WT, Andrews E, Couch M, Kojic EM, Cu-Uvin S, Palefsky J, Deal AM, Webster-Cyriaque J. Detection and quantitation of HPV in genital and oral tissues and fluids by real time PCR. Virol J 2010; 7: 194.

21. Rivera Z. R, Aguilera T. J, Larraín H A. Epidemiología del virus papiloma huma- no (HPV). Rev Chil Obstet Ginecol 2002; 67(6): 501-506.

22. Nasiell K, Roger V, Nasiell M. Behavior of mild cervical dysplasia during long term follow-up. Obstet Gynecol 1986;67: 665-669.

23. García PJ. Qué hay en el horizonte sobre el virus del papiloma humano, vacunas y el control del eáncer cervical. Rev Peru Med Exp Salud Pública 2007; 24(3): 272-279.

24. Seth R, Rippin J, Guo L, Jenkins D. Detection and quantitation of HPV gene expression using real-time PCR. Methods Mol Med 2005; 119: 61-72.

25. Palaoro L, Rocher A, De Torres R. The inflammatory genital. Respuesta inflamatoria genital en la detección de alteraciones por virus del papiloma humano. Acta Bioquím Clín Latinoam 2013; $47(3): 551-560$.

26. Smotkin D, Wettstein FO. Transeription of human papillomavirus type 16 early genes in a cervical cancer and a cancer-derived cell line and identification of the E7 protein. Proc Natl Acad Sci U S A 1986; 83(13): 4680-4684.

27. Pierry D, Weiss G, Lack B, Chen V, Fusco J. Intracellular human papilloma virus E6, E7 mRNA quantification predicts CIN $2+$ in cervical biopsies better than Papanicolaou screening for women regardless of aǵe. Arch Pathol Lab Med 2012; 136(8): 956-960.

28. Martínez G MJ. Diagnóstico microbiológiico de infecciones de transmisión Sexual: Parte II. ITS virales. Rev Chilena Infectol 2010; 27 (1): 60-64.

29. Origoni M, Cristoforoni P, Carminati G, Stefani C, Costa S, Sandri MT, Mariani L, Preti M. E6/E7 mRNA testing for human papilloma virus-induced high-grade cervical intraepithelial disease (CIN2/CIN3): a promising perspective. Ecancermedicalscience 2015; 9: 533. Doi: 10.3332/ecancer.2015.533

30. Peralta-Zaragoza O, Deas J, Gómez-Cerón C, García-Suastegui WA, Fierros-Zárate GDS, Jacobo-Herrera NJ. HPV-based screening, triage, treatment, and follow up strategies in the management of cervical intraepithelial neoplasia. Obstet Gynecol Int 2013; 2013: 912780.

31. Ciapponi A, Bardach A, Glujovsky D, Gibbons L, Picconi MA. Type-specific HPV pre- 
valence in cervical cancer and high-grade lesions in Latin America and the Caribbean: systematic review and meta-analysis. PLoSOne 2011; 6(10): e25493.

32. Wentzense N, von Knebel Doeberitz M Biomarkers in cervical cancer screening. Dis Mark 2007;23:315-330.
33. Spitkovsky D, Ermilova V, Kisseliov F. Protein p16 as a marker of dysplastic and neoplastic alterations in cervical epithelial cells. BMC Cancer 2004;4:58-68. 